\title{
Modeling Snow Depth for Improved Simulation of Snow-Vegetation-Atmosphere Interactions
}

\author{
John E. Strack, Glen E. Liston, and Roger A. Pielke Sr. \\ Department of Atmospheric Science, Colorado State University, Fort Collins, Colorado
}

(Manuscript received 25 November 2003, in final form 13 February 2004)

\section{ABSTRACT}

\begin{abstract}
The presence of snow and its relationship to surrounding vegetation significantly impacts the surface energy balance. For accurate atmospheric model simulations, the degree to which a snowpack can cover vegetation must be realistically represented. Both vegetation height and snow depth must be reasonably known to determine the amount of masking.

The Regional Atmospheric Modeling System/Land Ecosystem-Atmosphere Feedback, version two (RAMS/ LEAF-2) snow model was modified to simulate snow depth in addition to snow water equivalent and was driven offline with observed atmospheric forcing data. The model was run for five of the Boreal Ecosystem-Atmosphere Study (BOREAS) surface mesonet stations over the 1995/96 winter. The time evolution of simulated snow depth was compared with the observed snow depth. Averaged over the winter, the modeled snow depth at the four low-wind stations was within $0.09 \mathrm{~m}$ of the observations, and the average percent error was $27 \%$, while the one wind-blown station was considerably worse. The average depth error at all five stations was $\pm 0.08 \mathrm{~m}$. This is shown to be sufficient to reasonably account for the surface energy balance effects of vegetation protruding through the snow.
\end{abstract}

\section{Introduction}

Snow cover can significantly influence energy and moisture fluxes between the earth's surface and the atmosphere. Snow-covered surfaces absorb much less solar radiation than most other natural surfaces. For example, the typical albedo of snow for shortwave radiation ranges from 0.6 to 0.9 , while the albedo for most soils and vegetation is typically less than 0.3 (Pielke 2002, p. 408). In addition, snow-covered surfaces are limited to a maximum temperature of $0^{\circ} \mathrm{C}$. Finally, because of its low thermal conductivity, snow acts as an insulating blanket that decouples the soil and atmosphere.

A number of studies (Namias 1985; Cohen and Rind 1991; Baker et al. 1992; Leathers and Robinson 1993; Ellis and Leathers 1998; Taylor et al. 1998; Strack et al. 2003) have shown that the presence of snow can significantly reduce air temperatures through the processes described above. The strength of these cooling effects depends on the degree to which snow is able to mask the underlying surface (Liston 1995; Strack et al. 2003). When tall vegetation such as shrubs or trees protrude through the snowpack, they absorb more solar

Corresponding author address: John E. Strack, Department of Atmospheric Science, Colorado State University, 1371 Campus Delivery, Fort Collins, CO 80523-1371.

E-mail: jstrack@atmos.colostate.edu radiation and warm relative to the surrounding snow, thus providing a boundary layer heat source (Fig. 1). In Strack et al. (2003), changing the land-cover specification in the Colorado State University Regional Atmospheric Modeling System (CSU-RAMS; Cotton et al. 2003) from one that was masked by the snow (crop stubble) to one that had protruding vegetation (shrubs) produced sensible heat flux increases as large as $80 \mathrm{~W}$ $\mathrm{m}^{-2}$ during the day. The increased sensible heat flux produced a $6^{\circ} \mathrm{C}$ increase in afternoon air temperatures and a 200-300-m increase in the afternoon boundary layer height.

To determine the degree of masking by snow, both vegetation height and snow depth must be known. Knowing the correct snow depth is most critical for regions where fluctuations in snow depth lead to significant fluctuations in the amount of protruding vegetation. This occurs when the winter snowfall leads to snow accumulations that are comparable to the vegetation height. Snow depth is not as important in forests since the depth seldom, if ever, approaches the height of a typical tree and thus depth has proportionally less influence on the amount of protruding vegetation. Likewise, snow depth is not critical in regions of very short grass or bare ground, since any significant snowpack will immediately mask such surfaces. Shrubs and grass, having heights from 0.15 to $1.0 \mathrm{~m}$, are the primary landcover types in which snow depth changes can lead to significant fluctuations in the amount of protruding veg- 


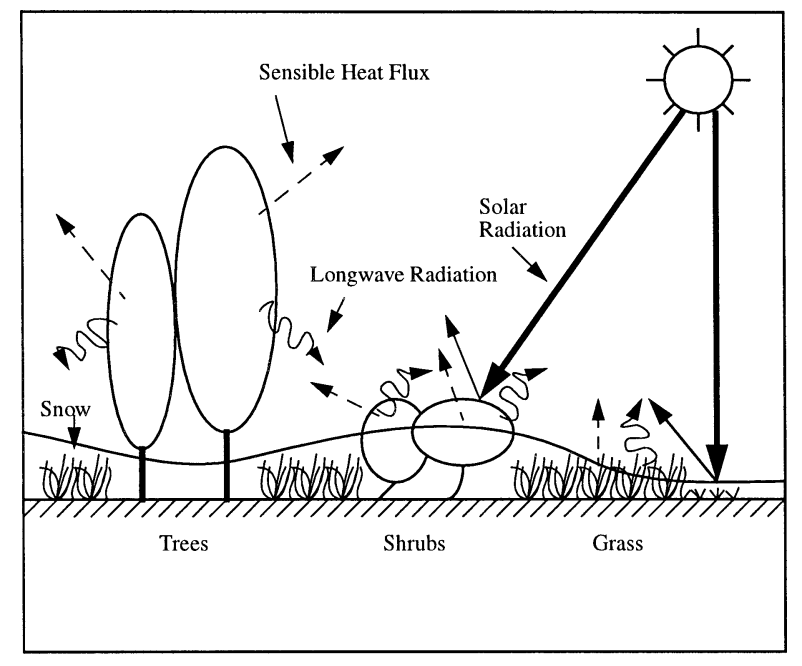

FIG. 1. Schematic showing vegetation of various heights protruding through a snowpack.

etation. Approximately $68 \%$ of the Northern Hemisphere land area that experiences snow (excluding Greenland) is covered with shrubs and grass (Liston 2004). Because of the widespread prevalence of the shrub and grass land-cover types, it is important that weather and climate models accurately estimate the degree to which they are masked by snow. Since snow depth is one of the parameters this masking is dependent on, it must be simulated as accurately as possible.

In recent years a number of sophisticated snow models have been introduced. Essery et al. (1999) describe a comparison to observations of several snow models including the Interactions between Soil, Biosphere, and Atmosphere (ISBA) scheme used in the Météo-France Action de Recherche Petite Echelle Grand Echelle (ARPEGE) GCM (Douville et al. 1995a,b), the CROCUS snow scheme used for avalanche forecasting (Brun et al. 1989), and the Instituto Nacional de Madrid (INM) scheme used for hydrological forecasting (Fernández 1998). SNTHERM is a sophisticated physically based one-dimensional snow energy and mass balance scheme (Jordan 1991) that has recently been used to simulate snow processes in the boreal forest (Hardy et al. 1998) and on sea ice (Jordan et al. 1999). Jin et al. (1999) tested a simplified version of SNTHERM against observations of snow depth at a grassland site in the French Alps as well as at the Boreal Ecosystem-Atmosphere Study (BOREAS) Southern Study Area Old Aspen site. In addition, Link and Marks (1999) tested the image version of the snowcover energy and mass-balance model (ISNOBAL), a two-layer snow mass and energy transfer scheme, against observations gathered during the BOREAS campaign. In yet another study, Yang et al. (1997) successfully tested the simple snow model of the Biosphere-Atmosphere Transfer Scheme (BATS) against observations taken at grassland sites in the former Soviet Union.
The purpose of the work described in this paper is to determine how well an upgraded version of the RAMS snow model simulates the time evolution of snow depth when driven with observed atmospheric forcing data. Here we describe modifications to the snow model used by RAMS version 4.30 (Cotton et al. 2003) that allow snow depth [in addition to snow water equivalent (SWE) simulated by the original model] to be predicted each time step. In addition, we discuss how the modified model was run in a single-column mode for several of the BOREAS stations (Sellers et al. 1997) and compare the results with observations. Even though the taiga region is not very representative of areas where vegetation protrusion is an issue, these stations are still adequate for testing how well the model can simulate the basic snowpack thermodynamic properties.

\section{Experimental design}

\section{a. Model description}

The model used in this study is similar to the original Land Ecosystem-Atmosphere Feedback, version two (LEAF-2) land surface scheme contained in RAMS and described by Walko et al. (2000). Four basic components - canopy air, vegetation, temporary surface water (snow), and soil-make up the model. The canopy air is defined as the air below the defined vegetation height when vegetation is present. When no vegetation is present, the "canopy" air is defined as the air in the laminar sublayer. At each time step, energy and moisture balances are carried out for each of these components. The turbulent sensible and latent heat fluxes between vegetation and canopy air are proportional to the fraction of total leaf area index (LAI) that protrudes above the snowpack. Similarly, the emission and absorption of longwave radiation and the absorption of shortwave radiation are proportional to the portion of the vegetation fraction that protrudes above the snow. The vegetation fraction is considered to be the fraction of the ground/ snow that is obscured by vegetation when viewed directly from above. This protruding LAI fraction and vegetation fraction decreases linearly to zero as the snow depth approaches the vegetation height.

The main differences between this offline model and the original model are 1) the snowpack treatment has been improved, and 2) soil moisture is forced from observations instead of predicted. Six major changes have been made to the snow component of the offline model. These changes include snow depth prediction, prediction of the falling-snow density, addition of a new snowpack compression rate, a new time-dependent snow albedo formulation, addition of a blowing-snow sublimation sink, and prediction of the snow skin temperature.

The new model keeps track of snow depth in addition to the liquid water equivalent. Depth gains and losses are calculated with simulated snow densities. The den- 
sity of newly fallen snow is calculated from (Anderson 1976)

$$
\rho_{s}=50+1.7\left(T_{\mathrm{wb}}-258.16\right)^{1.5},
$$

where $\rho_{s}$ is the snow density in kilograms per meters cubed, and $T_{\mathrm{wb}}$ is the wet-bulb temperature of the nearsurface air in kelvins. This equation is used to calculate precipitation density if the air temperature is less than or equal to $0^{\circ} \mathrm{C}$, otherwise the precipitation is assumed to be rain and the density is set to the liquid water value. The snow is allowed to compress with time at a rate adapted from the INM model described in Fernández (1998) and is given by

$$
\begin{aligned}
\rho_{s}(t+\delta t)=\rho_{s}(t)\langle 1+a \delta t \exp \{ & -b\left(T_{o}-T_{s}\right) \\
& \left.\left.-c\left[\rho_{s}(t)-\rho_{d}\right]\right\}\right\rangle,
\end{aligned}
$$

where $t$ is time, $a=2.8 \times 10^{-6} \mathrm{~s}^{-1}, b=0.02 \mathrm{~K}^{-1}, \rho_{d}$ $=250 \mathrm{~kg} \mathrm{~m}^{-3}, T_{o}=273.15 \mathrm{~K}, T_{s}$ is the snow temperature, and $\delta t$ is the time increment. The constant $c$ takes the value of 0 when $\rho_{s} \leq \rho_{d}$ and $460 \mathrm{~m}^{3} \mathrm{~kg}^{-1}$ when $\rho_{s}>\rho_{d}$. The maximum snow density is capped at a typical value (Liston et al. 1999a) for each of the snow-type categories in the Sturm et al. (1995) snowclassification system. We plan to incorporate the Sturm et al. snow-type categories, which have been mapped for the Northern Hemisphere, in LEAF-2. Finally, in addition to the influence of changing snow density, depth changes due to sublimation and melting are calculated from the mass losses due to these processes.

The new cold snow albedo is calculated using (Douville et al. 1995a)

$$
\alpha_{s}(t+\delta t)=\alpha_{s}(t)-\tau_{a} \frac{\delta t}{\tau_{1}},
$$

where $\alpha_{s}$ is the snow albedo, $\tau_{a}=0.008$, and $\tau_{1}=86$ $400 \mathrm{~s}$. For melting snow the albedo is calculated using (Douville et al. 1995a)

$$
\alpha_{s}(t+\delta t)=\left[\alpha_{s}(t)-\alpha_{\min }\right] \exp \left(\tau_{f} \frac{\delta t}{\tau_{1}}\right)+\alpha_{\min },
$$

where $\alpha_{\min }=0.5$ and $\tau_{f}=0.24$. New snow is assigned an albedo of 0.85 , and the albedo of an old snowpack is reset to 0.85 after $0.003 \mathrm{SWE}$ has fallen. Equations (3) and (4) gradually decrease the albedo to a minimum of 0.5 as the snow ages. This is an improvement over the original RAMS scheme where the albedo was not allowed to exceed 0.5. However, it should be noted that we did not account for the effects of forest litter, which can significantly lower snow albedo in some cases.

The offline model has also incorporated the blowingsnow sublimation scheme from a snow-transport model (SnowTran-3D; Liston and Sturm 1998). This scheme calculates the loss of snow due to sublimation of saltating and suspended particles. Since the runs described in this paper were carried out in a single-column manner, the snow transport features of SnowTran-3D could not be utilized. In order to get around this difficulty, it was assumed that any loss of snow due to horizontal transport of saltating and suspended particles was exactly offset by gains from the same process each time step. This implies that a relatively homogeneous snow surface existed around the stations at all times. In addition, it was assumed that at all times a sufficient fetch existed in the upwind direction for the concentration of saltating particles to be equal to the maximum equilibrium concentration as described in Liston and Sturm (1998).

Finally, the new version of the model was improved by the addition of a snow skin-temperature calculation. In the original model, the longwave radiation emission and sensible heat flux were calculated from the temperature of the top snow layer. This is not realistic since only a very thin layer at the surface actually responds directly to the atmosphere. The flow of heat between the bulk of the snow and this thin surface layer (skin) is much slower than the flow between the skin and the atmosphere. The skin temperature is calculated each time step by setting the sum of the terms of the surface energy balance to zero as shown below:

$$
H_{\mathrm{ss}}-\mathrm{SH}_{\mathrm{sc}}-\mathrm{LH}_{\mathrm{sc}}+\mathrm{LW}_{\mathrm{sa}}+\mathrm{LW}_{\mathrm{sv}}=0 .
$$

All of the terms in the above equation were computed as they are in LEAF-2 with the exception that the snow skin temperature is used in place of the top-layer bulk snow temperature. In Eq. (5) $H_{\mathrm{ss}}$ is the conduction of heat between the top snow layer and the snow skin and is given by

$$
H_{\mathrm{ss}}=K \frac{T_{s}-T_{\text {skin }}}{0.5 d},
$$

where $K$ is the thermal conductivity of the snow, $T_{s}$ is the top-layer snow temperature, $T_{\text {skin }}$ is the snow skin temperature, and $d$ is the thickness of the top snow layer. The $\mathrm{SH}_{\mathrm{sc}}$ term is the turbulent sensible heat flux given by

$$
\mathrm{SH}_{\mathrm{sc}}=c_{p} \rho_{a} \frac{T_{\mathrm{skin}}-T_{c}}{r_{d}},
$$

where $c_{p}$ is the specific heat of air at constant pressure, $\rho_{a}$ is the density of air, $T_{c}$ is the canopy air temperature, and $r_{d}$ is the aerodynamic resistance between the snow and the canopy air as defined in appendix D of Pielke (2002). The $\mathbf{L H}_{\mathrm{sc}}$ term is the turbulent latent heat flux given by

$$
\mathrm{LH}_{\mathrm{sc}}=L_{s} \rho_{a} \frac{r_{\mathrm{sat}}-r_{c}}{r_{d}},
$$

where $L_{s}$ is the latent heat of sublimation, $r_{\text {sat }}$ is the saturation water vapor mixing ratio at the snow skin temperature, and $r_{c}$ is the water vapor mixing ratio of the canopy air. The $\mathrm{LW}_{\mathrm{sa}}$ term is the net longwave radiation absorbed by the snow from the atmosphere and is given by

$$
\mathrm{LW}_{\mathrm{sa}}=\varepsilon_{s}\left(1-\Gamma_{s}\right)\left(R_{a}-\sigma T_{\text {skin }}^{4}\right),
$$


where $\sigma$ is the Stefan-Boltzmann constant, $\varepsilon_{s}$ is the emissivity of snow, $R_{a}$ is the longwave radiation emitted by the atmosphere, and $\Gamma_{s}$ is the portion of the vegetation fraction that protrudes above the snow. This exposed vegetation fraction is given by

$$
\Gamma_{s}=\max \left[0, \Gamma\left(1-\frac{z_{s}}{z_{v}}\right)\right],
$$

where $\Gamma$ is the vegetation fraction when the snow depth is equal to zero, $z_{s}$ is the snow depth, and $z_{v}$ is the height of the vegetation. The net longwave radiation absorbed by the snow from the vegetation, $\mathrm{LW}_{\mathrm{sv}}$, is given by

$$
\mathrm{LW}_{\mathrm{sv}}=\sigma \varepsilon_{s} \varepsilon_{v} \Gamma_{s}\left(T_{v}^{4}-T_{\text {skin }}^{4}\right),
$$

where $\varepsilon_{v}$ is the emissivity of the vegetation, and $T_{v}$ is the temperature of the vegetation.

All incoming solar radiation passes completely through the skin and is steadily attenuated as it passes through each of the snow layers below. The remaining solar radiation at the bottom of the snowpack is absorbed by the soil. When the snow skin temperature is predicted to be greater than $0^{\circ} \mathrm{C}$, the surface energy balance is then solved with the skin temperature set to $0^{\circ} \mathrm{C}$, and the resulting flux is defined as the energy available for melting. The melt flux is then used to melt a portion of the top snow layer. This method for calculating the snow skin temperature is very similar to that described in Liston et al. (1999b).

\section{b. Data description}

The data needed to drive the model included abovecanopy air temperature, atmospheric pressure, water vapor mixing ratio, precipitation, wind speed, soil moisture, soil temperature, incoming solar radiation, and downward atmospheric longwave radiation. Since the model required downward longwave radiation, we were limited to using the BOREAS stations that were augmented with "suite B" observations. These stations were Saskatoon, Saskatchewan, Canada $\left(52.2^{\circ} \mathrm{N}\right.$, $\left.106.6^{\circ} \mathrm{W}\right)$, the Old Aspen site in Prince Albert National Park, Saskatchewan $\left(53.6^{\circ} \mathrm{N}, 106.2^{\circ} \mathrm{W}\right)$, the Old Jack Pine site near Nipawin, Saskatchewan $\left(53.9^{\circ} \mathrm{N}\right.$, $\left.104.7^{\circ} \mathrm{W}\right)$, the Old Jack Pine site near Nelson House, Manitoba, Canada $\left(55.9^{\circ} \mathrm{N}, 98.6^{\circ} \mathrm{W}\right)$, and Flin Flon, Manitoba $\left(54.7^{\circ} \mathrm{N}, 101.7^{\circ} \mathrm{W}\right)$. The locations of these stations are shown in Fig. 2. All of the stations, except Saskatoon, were situated in the forest. Saskatoon was located in a grassland setting. All of the variables mentioned above, except for precipitation, were recorded as 15-min averages of 5-s observations. The precipitation measurements were recorded every hour. In addition, the snow depth, measured by an ultrasonic sensor, was recorded every hour. We have not made any wind corrections to the precipitation observations. Short periods, typically a few days or less, of missing data, were filled in using the interpolation scheme developed by Liston

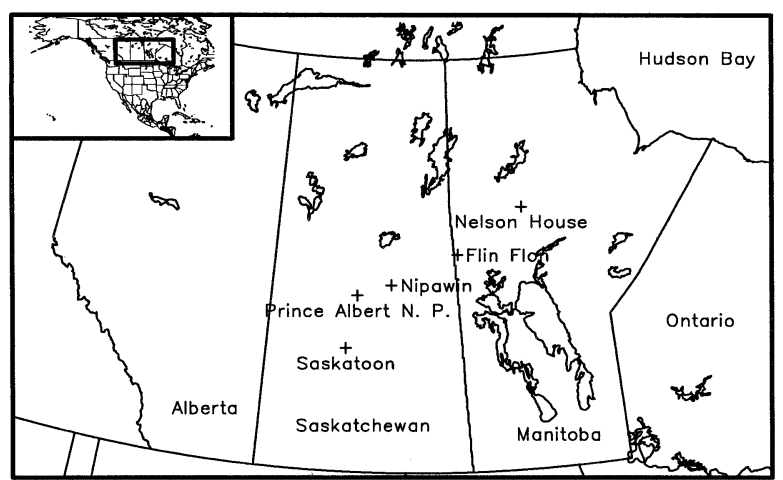

FIG. 2. Map showing the locations of the BOREAS surface mesonet stations.

and Elder (2003, manuscript submitted to J. Hydrometeor.). At each of the forest stations the above-canopy air temperature, relative humidity, wind speed, and radiation sensors were located on towers extending several meters above the canopy. The longwave sensors at all of the stations except Nelson House were located within $1 \mathrm{~km}$ of the suite A tower. The longwave radiation sensor for Nelson House was located about $15 \mathrm{~km}$ from the suite A tower. The precipitation and snow depth gauges were located is nearby clearings. More information on the BOREAS surface mesonet can be found in Shewchuk (1997). In addition, more information on the surface mesonet datasets used in this study can be found in Osborne et al. (1998a,b,c,d).

\section{c. Model configuration}

The offline snow model was used to simulate snow depth over the 1995/96 winter at the five BOREAS surface mesonet stations. The vegetation was defined as short grass with an LAI of 1.0, vegetation fraction of 0.98 , albedo of 0.2 , and a canopy height of $5 \mathrm{~cm}$. These vegetation parameters were used for the forest sites since the precipitation and snow depth gauges were located in clearings. The model was run at the snow depth gauge location in single-column mode, ignoring the forest canopy.

One 5-cm-thick soil layer and a maximum of six snow layers were used. The number of snow layers was automatically adjusted by the model based on the total snow mass present. The observed 10-cm-depth soil temperature was used as the lower boundary for the soil heat conduction equation, and the soil moisture was forced by the value observed at $10-\mathrm{cm}$ depth. The meteorological tower observations were used to drive the offline simulations; the model was run on a 15-s time step, and the driving variables were updated every 15 min. The observed above-canopy air temperature and mixing ratio communicated with the canopy air through fluxes computed from similarity theory as described for LEAF-2 in appendix D of Pielke (2002). The turbulent 
sensible heat flux between the canopy air and the air at observation height is given by

$$
\mathrm{SH}_{\mathrm{ca}}=c_{p} \rho_{a} \frac{T_{c}-T_{\mathrm{obs}}}{r_{a}},
$$

where $T_{\text {obs }}$ is the observed above-canopy temperature, and $r_{a}$ is the aerodynamic resistance, corrected for stability, between the canopy air and the observation height. The turbulent moisture flux between the canopy air and the air at observation height is given by

$$
E_{\mathrm{ca}}=\rho_{a} \frac{r_{c}-r_{\mathrm{obs}}}{r_{a}},
$$

where $r_{\mathrm{obs}}$ is the water vapor mixing ratio at the observation height.

\section{Results}

\section{a. Nipawin}

Because of the large amount of missing data in November and December of 1995 at the Nipawin station, the simulation was started at 0600 UTC 2 January 1996. The simulation terminated at 0000 UTC 30 May 1996. The model was initialized with $89.3 \mathrm{~kg} \mathrm{~m}^{-2}$ of snow on the ground in six layers. The initial snow mass on the ground was determined from the observed snow depth and an estimated density of $225 \mathrm{~kg} \mathrm{~m}^{-3}$ (Liston et al. 1999a) for the taiga snow classification (Sturm et al. 1995). The top-snow-layer temperature was set equal to the air temperature, and the temperatures of successively lower layers were increased linearly to the value of the soil temperature at the bottom layer. This method was used to initialize snow temperature for all the stations where snow existed at the start of the simulation. Simulations were also run where the initial snow temperature was set isothermally to either the soil or the air temperature. Virtually no differences were found between these simulations and the simulations with the linear profiles, suggesting little sensitivity to the initial snow temperature profile. The above-canopy air temperature, wind speed, and relative humidity were measured at $20.7 \mathrm{~m}$ above the ground for this station. Time series of air temperature and wind speed during the times of the simulations for all of the stations are shown in Figs. 3 and 4, respectively. During the period of the simulation the air temperature and wind speed averaged $-8.5^{\circ} \mathrm{C}$ and $2.0 \mathrm{~m} \mathrm{~s}^{-1}$, respectively, at Nipawin.

Figure 5a shows the time evolution of the simulated (thin line) and observed (bold line) snow depth during the course of the simulation. It can be seen from Fig. $5 \mathrm{a}$ that the model tended to overestimate the snow depth by amounts as great as $20 \mathrm{~cm}$, but generally less than $10 \mathrm{~cm}$. The average absolute difference between the two was $0.05 \mathrm{~m}$, or $26 \%$ of the observed. Even though precipitation errors are to be expected in this type of experiment, because of the difficult nature of measuring solid precipitation and the simple equation used to cal- culate precipitation density, the model did well at simulating the snow depth increases due to the precipitation events (solid circles in Fig. 5a) in mid-February, midMarch, and mid-April. The small melt event that occurred in mid-March was captured by the model, although its magnitude was underestimated. The large melt event that occurred in early April was overestimated, and the snow melted away entirely by mid-April before returning during the late-April accumulation event. The model reproduced the early-May final snowfree date fairly well. The period of near-constant snow with depth of about $0.05 \mathrm{~m}$ during the first half of May is believed to be erroneous since the temperatures during this time (Fig. 3a) were above freezing.

An average snow density of $152 \mathrm{~kg} \mathrm{~m}^{-3}$ was measured on 5 March near the Nipawin station (Hardy and Davis 1998). This density combined with a depth of $0.45 \mathrm{~m}$ yields an SWE of $0.069 \mathrm{~m}$, which is significantly less than the simulated SWE of $0.110 \mathrm{~m}$. The simulated SWE is larger than the observed SWE since we initialized the snow mass based on the "typical" taiga density of $225 \mathrm{~kg} \mathrm{~m}^{-3}$, which appears to be greater than the observed values. Two percent of the simulated snowpack at Nipawin was lost to sublimation. Finally, Fig. 6 shows the evolution of the modeled snow albedo during the simulations for all of the stations. It ranges from a maximum of 0.85 immediately following snow events to a minimum of 0.5 during periods between snow accumulation events.

\section{b. Nelson House and Prince Albert}

The simulation for Nelson House was started at 0000 UTC 1 February 1996 and terminated at 0000 UTC 30 May 1996. The long period of missing data spanning the entire month of January prevented an earlier start time. Air temperature, relative humidity, and wind speed were measured at 15.8 and $23.7 \mathrm{~m}$ above the ground, at Nelson House and Prince Albert, respectively. The average air temperature and wind speed at Nelson House were $-8.4^{\circ} \mathrm{C}$ and $2.5 \mathrm{~m} \mathrm{~s}^{-1}$, respectively. The model was initialized, using the same method discussed above, with $99.4 \mathrm{~kg} \mathrm{~m}^{-2}$ of snow in six layers. The simulation for Prince Albert was started at 0000 UTC 23 November 1995 and terminated on 0000 UTC 30 May 1996. Again, long periods of missing data prevented an earlier start date. Average air temperature and wind speed at Prince Albert were $10.9^{\circ} \mathrm{C}$ and $2.1 \mathrm{~m} \mathrm{~s}^{-1}$, respectively. An initial snow mass, spread over six layers, of $85.5 \mathrm{~kg} \mathrm{~m}^{-2}$ was used.

Figures $5 \mathrm{~b}$ and $5 \mathrm{c}$ show the simulated and observed snow depth evolution for the Nelson House and Prince Albert stations. The difference between observed and simulated snow depths at Nelson House was generally $0.1 \mathrm{~m}$ or less for most of the simulation, with the exception of the end-of-season melt period in late April and early May when the difference reached a peak of $0.5 \mathrm{~m}$ (Fig. 5b). The average absolute difference between the 
a

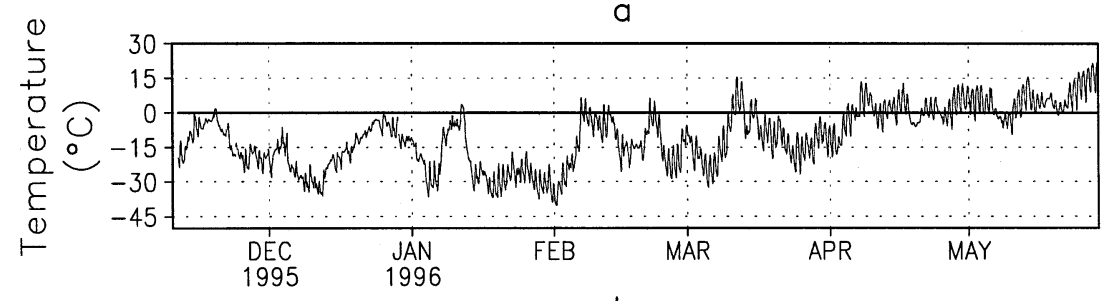

b
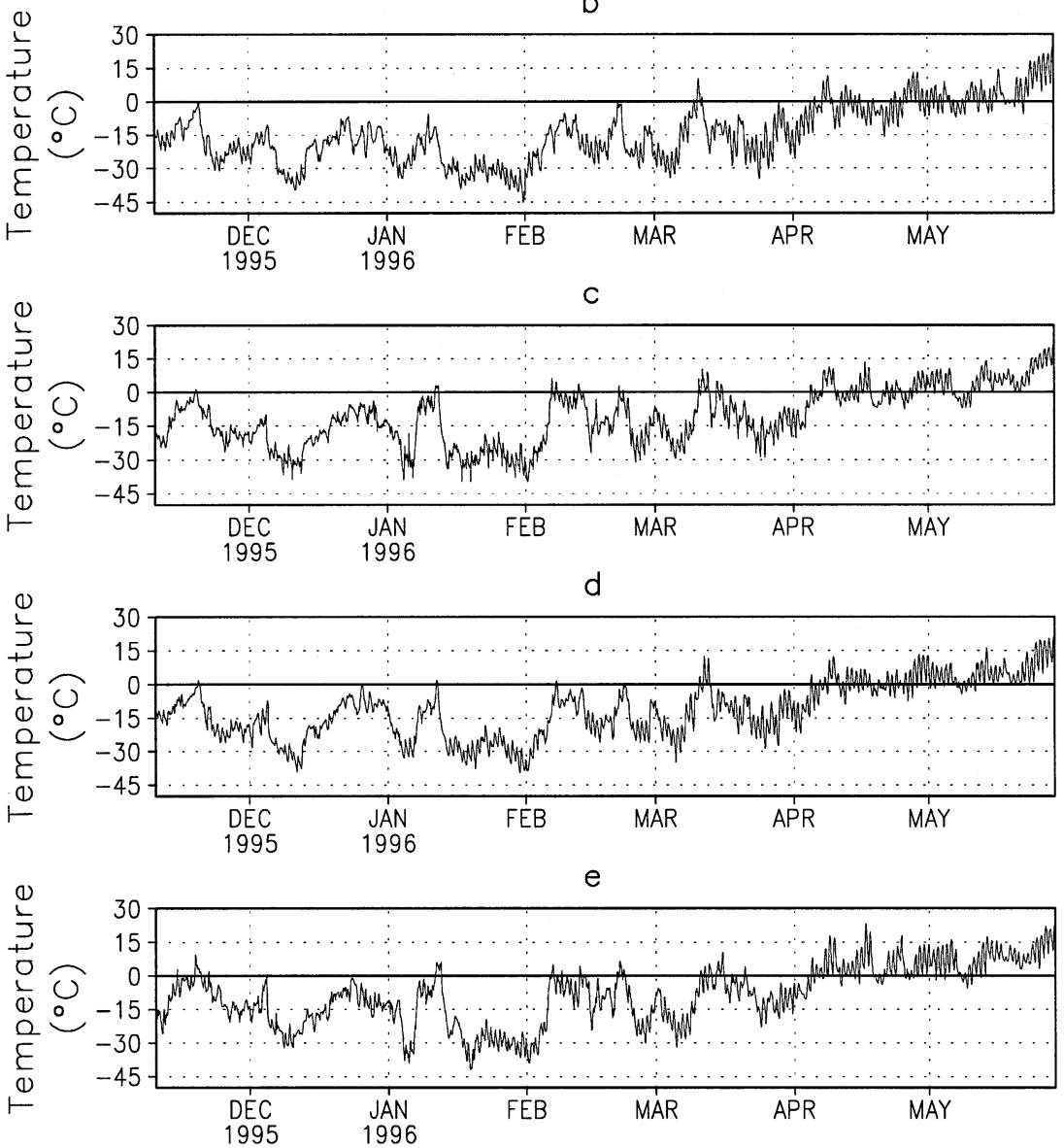

FIG. 3. Observed air temperature at (a) Nipawin, (b) Nelson House, (c) Prince Albert, (d) Flin Flon, and (e) Saskatoon.

simulated and observed snow depths was about $0.10 \mathrm{~m}$, or $28 \%$ of the observed value. The end-of-season melt off during late April and early May was handled poorly, with the simulated snow-free date occurring 12 days ahead of the observed. The inability of the model to represent snowpack shading by the surrounding forest is a possible explanation for the simulated snow melting much faster during the last half of April. The snow depth sensor was located in a forest clearing, while the radiometer, used to drive the incoming solar radiation in the model, was located above the forest canopy. During the morning and evening hours when the sun was relatively low in the sky, the forest likely produced shadows across the clearing. Link and Marks (1999) ran similar simu- lations at Nipawin and Nelson House with the ISNOBAL model for the 1994/95 winter. They used a canopy radiative transfer scheme to simulate the subcanopy radiation and were better able to simulate the snow-free dates. Three percent of the simulated snowpack at Nelson House was lost to sublimation.

Figure $5 \mathrm{c}$ shows that the model overestimated the snow depth at Prince Albert by 0.05 to $0.1 \mathrm{~m}$ during December. A string of missing snow depth data extending from about mid-January to mid-February inhibits any conclusion on the model's ability during that time. From mid-February to March the model did fairly well while the melting events during mid-April were generally underestimated. During the last few days of April the simulated snowpack 
a
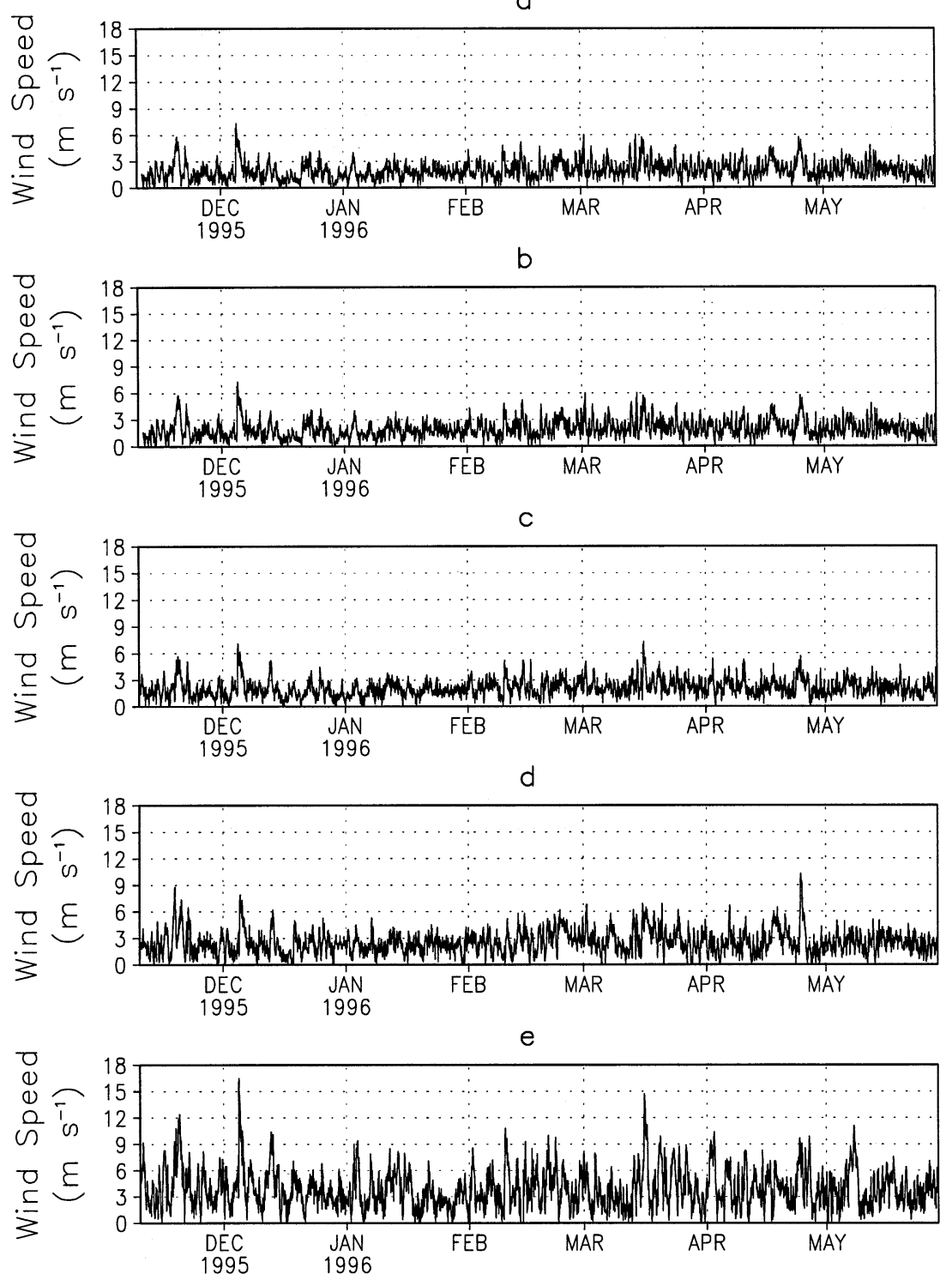

FIG. 4. Observed wind speed at (a) Nipawin, (b) Nelson House, (c) Prince Albert, (d) Flin Flon, and (e) Saskatoon.

began to ablate while the observed snow depth increased slowly. This could be due to the model predicting rain when wet snow was actually falling. For simplicity, the model defines precipitation as snow when the air temperature is at or below $0^{\circ} \mathrm{C}$, but in reality snow can fall when the temperature near the surface is as much as $5^{\circ} \mathrm{C}$ above freezing (Auer 1974). During the first half of May the simulated snowpack melts away rapidly and is completely gone by 15 May, while the observed snow depth appears to be $0.35 \mathrm{~m}$. However, Hardy et al. (1998) found, through an examination of the net surface albedo, that the snow actually melts off by 29 April, meaning the snow in our model took 16 days longer to melt off. Hardy et al. (1998) were able to simulate this snow-free date quite well with SNTHERM. An average snow density of $159 \mathrm{~kg} \mathrm{~m}^{-3}$ was measured on 4 March near the Prince Albert station (Hardy and Davis 1998). This density combined with a depth of $0.62 \mathrm{~m}$ yields an SWE of 0.099 $\mathrm{m}$, which is significantly less than the simulated SWE of $0.130 \mathrm{~m}$. Again, the simulated SWE is larger than the observed SWE since we initialized the snow mass based on the "typical" taiga density of $225 \mathrm{~kg} \mathrm{~m}^{-3}$, which is greater than the observed values. The extra SWE may explain the delayed snow-free date in this case. The average absolute difference between the observed and simulated snow depths at Prince Albert was $0.07 \mathrm{~m}$, or $18 \%$ of the observed value. Four percent of the simulated Prince Albert snowpack was lost to sublimation. 

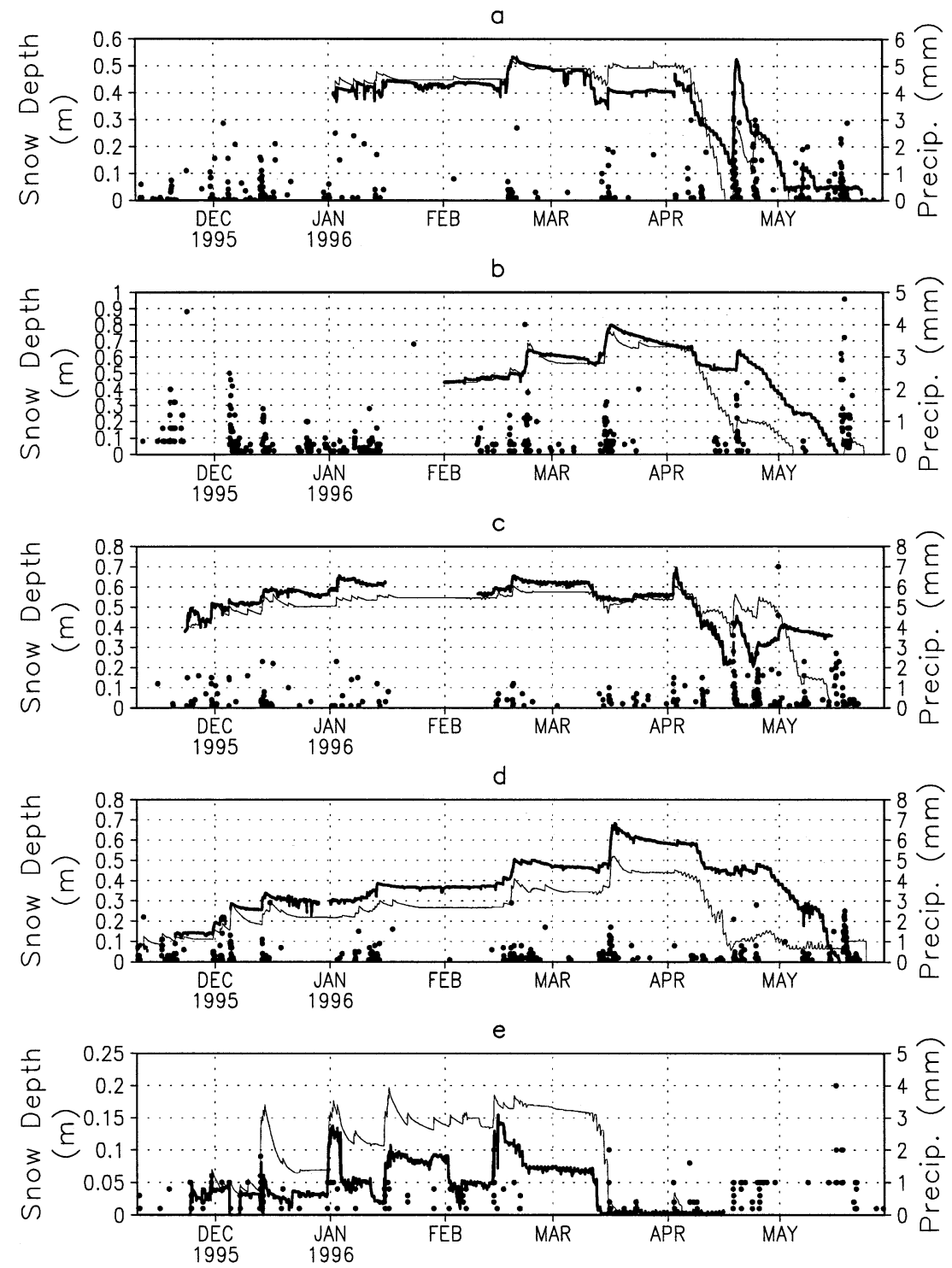

FIG. 5. Time evolution of observed (bold line) and simulated (thin line) snow depth and observed hourly precipitation (solid circles) for (a) Nipawin, (b) Nelson House, (c) Prince Albert, (d) Flin Flon, and (e) Saskatoon.

\section{c. Flin Flon}

The simulation for Flin Flon began at 0000 UTC 10 November 1995 and ended 0000 UTC 30 May 1996. Air temperature, relative humidity, and wind speed were measured at $17.9 \mathrm{~m}$ above the ground. The average air temperature and wind speed during the period of the simulation were $-11.3^{\circ} \mathrm{C}$ and $2.5 \mathrm{~m} \mathrm{~s}^{-1}$, respectively. The model was initialized with $15.8 \mathrm{~kg} \mathrm{~m}^{-2}$ of snow. Figure $5 \mathrm{~d}$ shows the time series of simulated and observed snow depths at this station. The absolute difference between the simulated and observed snow depths was $0.13 \mathrm{~m}$, or $34 \%$ of the observed value. The model appeared to compress the snow too quickly during the month of December. The erroneously fast compression leads to a general underestimation of the snow depth from mid-December through mid-April. The accumulations in mid-February and mid-March appear to be well simulated. The simulated snowpack completely melts by 4 May, while the observed snow lingered until 17 May. The more rapid melt of the simulated snowpack could again be due to the lack of shading in the model. Ten percent of the simulated snowpack sublimated.

Since the soil was saturated during much of April and May the melted snow formed 0.1-m-deep standing water in the model during the first half of May (Fig. 5d). It should be noted that the Fig. 5 snow depth plots show the total surface water depth including both liquid and frozen fractions. So, even though it appears snow ex- 

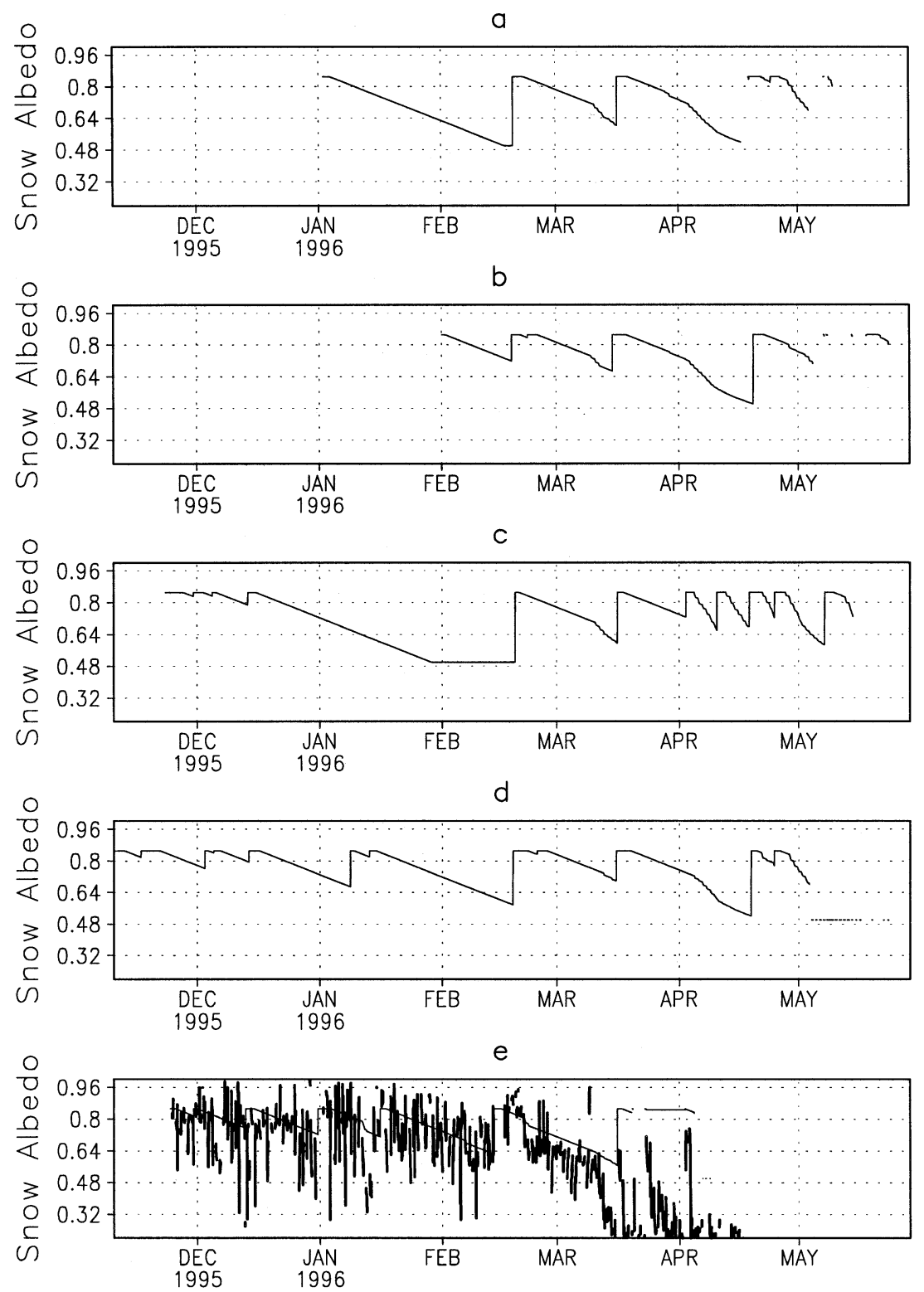

FIG. 6. Simulated snow albedo at (a) Nipawin, (b) Nelson House, (c) Prince Albert, (d) Flin Flon, and (e) Saskatoon. The bold line in (e) represents the observed net surface albedo computed from the incoming and reflected solar radiation.

isted during the first half of May, an inspection of the snow liquid water fraction (not shown) reveals only standing liquid water existed during this time period. In the model, the snowpack was not allowed to have more than $10 \%$ of its mass in the form of liquid water. Any amount that exceeded this limit percolated into the soil, unless the soil was saturated as in the case mentioned above.

\section{d. Saskatoon}

As a grassland site instead of a forest clearing, Saskatoon was significantly different than the other stations.
The temperature and relative humidity sensors were located at $1.7 \mathrm{~m}$, and the wind speed sensor was at $10.0 \mathrm{~m}$. The average air temperature and wind speed during the period of the simulation were $-13.4^{\circ} \mathrm{C}$ and $3.9 \mathrm{~m} \mathrm{~s}^{-1}$, respectively. The simulation was started at 0000 UTC 24 November 1995 and terminated at 000016 April 1996. No snow was present at the beginning of the simulation.

The model overestimated the snow depth during much of the simulation (Fig. 5e). The average absolute difference between the observed and simulated snow depths was $0.05 \mathrm{~m}$, or $132 \%$ of the observed value. The model captured the accumulation events around the first 
and middle parts of January; however, the mid-December and mid-February events were overestimated and underestimated, respectively. The lack of wind-driven horizontal snow transport in the model is a likely reason for these errors. Since this station was located on the prairie where the peak winds were stronger (Fig. 4e), transport is expected to be a larger factor than in the forest clearings. In addition, the lack of a wind-dependent new-snow algorithm might be another reason for the overestimation of snow depth since new-snow density in windy areas is often greater than that predicted by temperature alone. The influence of wind at Saskatoon was evident in the much larger sublimation flux simulated by the model there. At Saskatoon $43 \%$ of the simulated snowpack was lost to sublimation (13\% during blowing-snow events) compared to less than 5\% (with no blowing snow) in most of the forest clearings. Finally, Fig. 6e shows a plot of the modeled snow albedo (thin line) along with the observed ratio of reflected shortwave radiation to incoming shortwave radiation (bold line), which represents the net surface albedo. Since the primary vegetation at the Saskatoon site is short grass we can assume this quantity closely approximates that of the snow albedo. An examination of the figure shows that the modeled albedo is fairly close to the observed value until early March. Starting in early March the observed net surface albedo drops below the simulated snow albedo. This is likely due to patches of grass emerging as the snow begins to melt.

\section{Discussion}

Averaged over the winter, the modeled snow depth at the four low-wind stations was within $0.09 \mathrm{~m}$ of the observations, and the average percent error was $27 \%$, while the one wind-blown station, Saskatoon, was considerably worse. The average depth error at all five stations was $\pm 0.08 \mathrm{~m}$. In order to gain some idea of how significant these errors would be to the calculation of the turbulent sensible and longwave radiative heat fluxes from protruding vegetation, a simple conceptual model of a shrub patch partially buried in snow was developed. This model was used to simulate the change in turbulent sensible and longwave radiative heat fluxes from the shrubs as a function of snow depth. The heat fluxes generated by the shrub were calculated for hypothetical atmospheric conditions as the snow depth was varied from $0 \mathrm{~m}$ to the $1.0-\mathrm{m}$ shrub height. The turbulent sensible and longwave radiative fluxes were calculated with the same equations used by LEAF-2. The sensible heat flux is calculated using

$$
\mathrm{SH}_{\mathrm{vc}}=2.2 \gamma_{s} c_{p} \rho_{a} \frac{\left(T_{v}-T_{c}\right)}{r_{b}},
$$

where the portion of the LAI that protrudes above the snow, $\gamma_{s}$, is
TABLE 1. Values of vegetation and atmospheric parameters used in the heat flux sensitivity experiments.

\begin{tabular}{lll}
\hline \hline Symbol & \multicolumn{1}{c}{ Description } & \multicolumn{1}{c}{ Value } \\
\hline$\gamma$ & Leaf area index & 2 \\
$\sigma$ & Stefan-Boltzmann constant & $5.67 \times 10^{-8} \mathrm{~W} \mathrm{~m}^{-2} \mathrm{~K}^{-4}$ \\
$\Gamma$ & Vegetation fraction & 0.8 \\
$\varepsilon_{s}$ & Snow emissivity & 0.99 \\
$\varepsilon_{v}$ & Vegetation emissivity & 0.96 \\
$c_{p}$ & Specific heat of air at & $1004 \mathrm{~J} \mathrm{~kg}^{-1} \mathrm{~K}^{-1}$ \\
& $\quad$ constant pressure \\
$z o_{\text {snw }}$ & Snow roughness length & $0.001 \mathrm{~m}$ \\
$z o_{\text {veg }}$ & Vegetation roughness length & $0.05 \mathrm{~m}$ \\
$z_{s}$ & Snow depth & $0.01-1.0 \mathrm{~m}$ \\
$z_{v}$ & Vegetation height & $1 \mathrm{~m}$ \\
$\rho_{a}$ & Air density & $1.3 \mathrm{~kg} \mathrm{~m}^{-3}$ \\
\hline
\end{tabular}

$$
\gamma_{s}=\max \left[0, \gamma\left(1-\frac{z_{s}}{z_{v}}\right)\right],
$$

and the resistance between the vegetation and the canopy air, $r_{b}$, is

$$
r_{b}=\frac{\left(1+0.55 \gamma_{s}\right)}{0.01}\left[\max \left(0.1, u_{*}\right) 116.6\right]^{-1 / 2} .
$$

The friction velocity, $u_{*}$, is calculated from surface similarity theory (Louis et al. 1981) and is dependent upon the net surface roughness, $z_{o}$,

$$
z_{o}=z o_{\text {veg }} \max \left(0,1-\frac{z_{s}}{z_{v}}\right)+z o_{\text {snw }} \min \left(1, \frac{z_{s}}{z_{v}}\right) .
$$

The variables $T_{v}$ and $T_{c}$ represent vegetation and canopy air temperatures, respectively. The longwave radiation emitted by the vegetation to the snow is

$$
\mathrm{LW}_{\mathrm{vs}}=\Gamma_{s} \varepsilon_{s} \varepsilon_{v} \sigma T_{v}^{4} .
$$

Table 1 lists the remaining variables in these equations that have not been defined. The vegetation and canopy air temperatures were set to 268 and $267 \mathrm{~K}$, respectively, and the $10-\mathrm{m}$ wind speed was set to $5 \mathrm{~m} \mathrm{~s}^{-1}$. Figure $7 \mathrm{a}$ shows the variation in sensible heat flux with changing snow depth. The line with solid circles represents the heat flux simulated at each snow depth, and the thin solid lines represent $0.08-\mathrm{m}$ deviations from the actual snow depth. The average error of $0.08 \mathrm{~m}$ in snow depth produced an average $17 \mathrm{~W} \mathrm{~m}^{-2}$ sensible heat flux error. Figure $7 \mathrm{~b}$ shows similar longwave radiative heat flux variation with snow depth. The average longwave radiative flux error was also $17 \mathrm{~W} \mathrm{~m}^{-2}$. The conceptual model discussed above assumes that the vegetation fraction and LAI will decrease linearly as the snow approaches the height of the shrub. One should note that this assumption itself could lead to heat flux errors of a similar magnitude to those produced by incorrect snow depth. However, the focus of this paper is improving the accuracy of the simulated snow depths. 

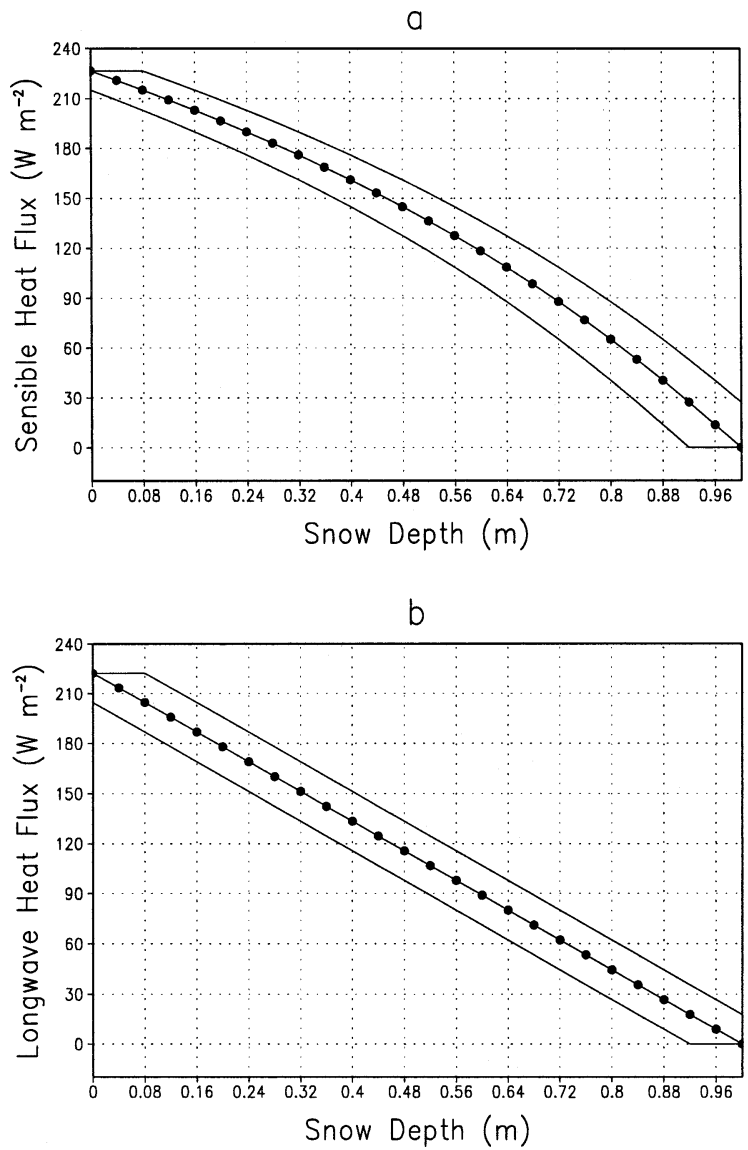

FIG. 7. (a) Simulated sensible heat flux emission from a hypothetical 1-m-tall shrub patch with varying snow depth. The line with solid circles represents the sensible heat flux at each snow depth. The upper and lower thin solid lines represent the heat flux for snow depth error of -0.08 and $+0.08 \mathrm{~m}$, respectively. (b) Same as in (a), except for longwave radiative flux.

\section{Summary and future work}

A modified version of the RAMS/LEAF-2 snow scheme was run offline from RAMS using five of the BOREAS surface mesonet stations. The modifications included adding a snow depth calculation; predicting the density of new snowfall; modifying the snow compression rate; improving the snow albedo formulation, including a blowing-snow sublimation routine; and calculating the snow skin temperature. Observed air temperature, water vapor mixing ratio, wind speed, precipitation, soil temperature and moisture, solar radiation, and downward atmospheric longwave radiation were used to drive the offline model. Simulated and observed snow depths were compared; for the five stations examined, the average absolute difference between the simulated and observed depths was $0.08 \mathrm{~m}$.

An overall goal of this study was to determine the snow model's ability to simulate snow depth. An accurate estimate of the snow depth is necessary to determine the degree to which vegetation is masked by the snow. The average $0.08-\mathrm{m}$ snow depth error suggests the model would give the poorest estimates of surface masking in grassy areas where the snow depth error is a relatively large percentage of the vegetation height. For the case of shrubs, which are typically higher, the snow depth error would have a smaller influence on the estimate of surface masking. The $0.08-\mathrm{m}$ snow depth error produced a relatively small error $\left(17 \mathrm{~W} \mathrm{~m}^{-2}\right)$ in the simulated longwave radiative and turbulent sensible heat fluxes from a hypothetical 1.0-m-tall shrub.

A logical next step in our effort to accurately simulate surface fluxes in snow-shrub environments is to test the model-generated surface heat fluxes against observations. We also plan to run more point simulations, similar to those described in this paper, at grassland sites. In addition, we plan to incorporate a wind-dependent new-snow density algorithm into the model. This work is currently in progress and utilizes the fluxes and snow depth distributions measured during the 2002/03 winter Fluxes Over Snow Surfaces Phase II (FLOSS II) field campaign. The offline model will be run with a single grid cell centered over the flux tower and will have multiple land-cover patches representing the dominant vegetation species surrounding the tower. In addition, the Subgrid Snow Distribution (SSNOWD) scheme (Liston 2004) will be used to represent the patchy nature of melting snowpacks. Once the fluxes have been verified against observed values, the new snow model will be implemented and tested within RAMS.

Acknowledgments. This work was funded by NOAA Grant NA17RJ1228 Amendment 6, NSF Grants DEB0217631 and 0229973 001, and NASA Fellowship Grant NGT5-30527.

\section{REFERENCES}

Anderson, E. A., 1976: A point energy and mass balance model of a snow cover. NOAA Tech. Rep. NWS-19, 150 pp.

Auer, A. H., 1974: The rain versus snow threshold temperature. Weatherwise, 27, 67.

Baker, D. G., D. L. Ruschy, R. H. Skaggs, and D. B. Wall, 1992: Air temperature and radiation depressions associated with a snow cover. J. Appl. Meteor., 31, 247-254.

Brun, E., E. Martin, V. Simon, C. Gendre, and C. Coleou, 1989: An energy and mass balance model of snowcover suitable for operational avalanche forecasting. J. Glaciol., 35, 333-342.

Cohen, J., and D. Rind, 1991: The effect of snow cover on climate. J. Climate, 4, 689-706.

Cotton, W. R., and Coauthors, 2003: RAMS 2001: Current status and future directions. Meteor. Atmos. Phys., 82, 5-29.

Douville, H., J.-F. Royer, and J.-F. Mahfouf, 1995a: A new snow parameterization for the Météo-France climate model. Part I: Validation in stand-alone experiments. Climate Dyn., 12, 21-35. $\ldots, \ldots$, and —_, 1995b: A new snow parameterization for the Météo-France climate model. Part II: Validation in a 3-D GCM experiment. Climate Dyn., 12, 36-52.

Ellis, A. W., and D. J. Leathers, 1998: A quantitative approach to evaluating the effects of snow cover on cold airmass temperatures across the U.S. Great Plains. Wea. Forecasting, 13, 688701.

Essery, R., E. Martin, H. Douville, A. Fernández, and E. Brun, 1999: A comparison of four snow models using observations from an alpine site. Climate Dyn., 15, 583-593. 
Fernández, A., 1998: An energy balance model of seasonal snow evolution. Phys. Chem. Earth, 23, 661-666.

Hardy, J. P., and R. E. Davis, cited 1998: BOREAS HYD-03 snow water equivalent: 1996. [Available online at http://www.daac. ornl.gov.]

- — , R. Jordan, W. Ni, and C. E. Woodcock, 1998: Snow ablation modeling in a mature aspen stand of the boreal forest. Hydrol. Processes, 12, 1763-1778.

Jin, J., X. Gao, S. Sorooshian, Z.-L. Yang, R. Bales, R. E. Dickinson, S.-F. Sun, and G.-X. Wu, 1999: One-dimensional snow water and energy balance model for vegetated surfaces. Hydrol. Processes, 13, 2467-2482.

Jordan, R., 1991: A one-dimensional temperature model for a snow cover: Technical documentation for SNTHERM.89. Special Rep. 91-16, U.S. Army Cold Regions Research and Engineering Laboratory, Hanover, NH, 49 pp.

-, E. L Andreas, and A. P. Makshtas, 1999: Heat budget of snowcovered sea ice at North Pole 4. J. Geophys. Res., 104, 77857806.

Leathers, D. J., and D. A. Robinson, 1993: The association between extremes in North American snow cover extent and United States temperatures. J. Climate, 6, 1345-1355.

Link, T., and D. Marks, 1999: Distributed simulation of snowcover mass- and energy-balance in the boreal forest. Hydrol. Processes, 13, 2439-2452.

Liston, G. E., 1995: Local advection of momentum, heat, and moisture during the melt of patchy snow covers. J. Appl. Meteor., 34, $1705-1715$.

— 2004: Representing subgrid snow cover heterogeneities in regional and global models. J. Climate, 17, 1381-1397.

- , and M. Sturm, 1998: A snow-transport model for complex terrain. J. Glaciol., 44, 498-516.

— , R. A. Pielke Sr., and E. M. Greene, 1999a: Improving firstorder snow-related deficiencies in a regional climate model. $J$. Geophys. Res., 104, 19 559-19 567.

_- J.-G. Winther, O. Bruland, H. Elvehoey, and K. Sand, 1999b: Below-surface ice melt on the coastal Antarctic ice sheet. $J$. Glaciol., 45, 273-285.

Louis, J. F., M. Tiedke, and J.-F. Geleyn, 1981: A short history of the PBL parameterization at the ECMWF. Proc. Workshop on
Planetary Boundary Layer Parameterization, Shinfield Park, Reading, United Kingdom, ECMWF, 59-80.

Namias, J., 1985: Some empirical evidence for the influence of snow cover on temperature and precipitation. Mon. Wea. Rev., 113, 1542-1553.

Osborne, H., K. Young, V. Wittrock, and S. Shewchuck, cited 1998a: BOREAS/SRC AMS suite A surface meteorological and radiation data: 1995. [Available online at http://www.daac.ornl.gov.] , — — $\longrightarrow$, and $\longrightarrow$, cited 1998b: BOREAS/SRC AMS suite B surface meteorological and radiation data: 1995. [Available online at http://www.daac.ornl.gov.]

,,--- , and - , cited 1998c: BOREAS/SRC AMS suite A surface meteorological and radiation data: 1996. [Available online at http://www.daac.ornl.gov.]

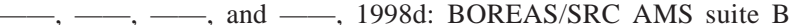
surface meteorological and radiation data: 1996. [Available online at http://www.daac.ornl.gov.]

Pielke, R. A., 2002: Mesoscale Meteorological Modeling. 2d ed. Academic Press, 676 pp.

Sellers, P. J., and Coauthors, 1997: BOREAS in 1997: Experiment overview, scientific results, and future directions. J. Geophys Res., 102, 28 731-28 769.

Shewchuk, S. R., 1997: Surface mesonet for BOREAS. J. Geophys Res., 102, 29 077-29082.

Strack, J. E., R. A. Pielke Sr., and J. Adegoke, 2003: Sensitivity of model-generated daytime surface heat fluxes over snow to landcover changes. J. Hydrometeor., 4, 24-42.

Sturm, M., J. Holmgren, and G. E. Liston, 1995: A seasonal snow cover classification system for local to global applications. $J$. Climate, 8, 1261-1283.

Taylor, C. M., R. J. Harding, R. A. Pielke Sr., P. L. Vidale, R. L. Walko, and J. W. Pomeroy, 1998: Snow breezes in the boreal forest. J. Geophys. Res., 103, 23 087-23 101.

Walko, R. L., and Coauthors, 2000: Coupled atmosphere-biophysicshydrology models for environmental modeling. J. Appl. Meteor. 39, 931-944.

Yang, Z.-L., R. E. Dickinson, A. Robock, and K. Y. Vinnikov, 1997: Validation of the snow submodel of the Biosphere-Atmosphere Transfer Scheme with Russian snow cover and meteorological observational data. J. Climate, 10, 353-373. 